\title{
A longitudinal study of feed contamination by European starling excreta in Ohio dairy farms (2007-2008)
}

\author{
G. A. Medhanie, ${ }^{* 1}$ D. L. Pearl, ${ }^{*}$ S. A. McEwen, ${ }^{*}$ M. T. Guerin, ${ }^{*}$ C. M. Jardine, $†$ J. Schrock, $\ddagger$ and J. T. LeJeune \\ *Department of Population Medicine, and \\ †Department of Pathobiology, Ontario Veterinary College, University of Guelph, Guelph, ON, N1G 2W1, Canada \\ †Food Animal and Health Research Program, Ohio Agricultural Research and Development Center, The Ohio State University, Wooster 44691
}

\section{ABSTRACT}

The objectives of this study were to understand the temporal pattern of contamination of cattle feed by starling excrement on dairy farms and to evaluate the temporal pattern in recovering Escherichia coli O157:H7 or Salmonella in relation to the absolute mass of excrement recovered. A longitudinal study was conducted on 15 dairy farms in Ohio from July 2007 to October 2008. One open-topped tray filled with bird feed was placed near a cattle feeding site; bird excrement from the tray was weighed monthly for 12 consecutive months. Linear regression models with a random intercept for farm were computed to examine the association between the absolute weight of excrement recovered each month or the farm-specific standard score for weight of excrement, and month or season. Exact logistic regression was used to determine whether an association between recovering E. coli O157:H7 or Salmonella was present and the amount of excrement recovered and season. A spatial scan statistic was used to test for evidence of spacetime clustering of excrement, based on the standard score for the weight of the excrement, among our study farms. A total of 5 of 179 excrement samples (2.79\%) were positive for $E$. coli $\mathrm{O} 157: \mathrm{H} 7$ and $2(1.12 \%)$ were positive for Salmonella. A significantly higher level of contamination with excrement was observed during the winter. The odds of recovering a pathogen increased with the amount of excrement recovered and decreased if the excrement was collected in the winter. A spatiotemporal cluster of contamination with excrement was detected. These findings provide basic information for future quantitative microbial risk assessments concerning the role of starlings in spreading enteric pathogens on dairy farms.

Key words: European starling, fecal weight, month, multilevel

Received February 12, 2014.

Accepted April 15, 2014.

${ }^{1}$ Corresponding author: gasmelas@uoguelph.ca

\section{INTRODUCTION}

European starlings (Sturnus vulgaris) are responsible for large economic losses. The estimated loss merely from their destruction and consumption of grain was estimated close to 800 million dollars per year (Pimentel et al., 2000). In addition to consuming large amounts of cattle feed, these birds contaminate feed and the farm environment with droppings and spread zoonotic and animal pathogens (Feare et al., 1992; Johnson and Glahn, 1994), which is a concern for food safety. Zoonotic pathogens, including Escherichia coli O157:H7 (LeJeune et al., 2008), Salmonella spp. (Carlson et al., 2011), and Campylobacter spp. (Sanad et al., 2013) have been detected in starling feces, and ingestion of feed contaminated with bird feces is a possible route of infection for cattle (Daniels et al., 2003). Genotypically identical isolates of Campylobacter jejuni were recovered from the feces of starlings and cattle on the same dairy farm (Sanad et al., 2013), and similar isolates of E. coli O157:H7 from starlings and cattle on different dairy farms were identified using multiple-locus variable-nucleotide tandem repeat analysis (Williams et al., 2011). Transmission by wild birds was the most likely explanation when the same subtypes of $E$. coli O157:H7 were identified from feedlots approximately 50 to $100 \mathrm{~km}$ apart (Van Donkersgoed et al., 2001; Wetzel and LeJeune, 2006).

Livestock facilities are attractive to starlings because of the availability of large quantities of feed and water (Johnson and Glahn, 1994; Linz et al., 2007). This is particularly true during the period from late summer through late winter when insects and other invertebrate prey are rare (Feare et al., 1992).

Previous researchers have suggested that starlings are more attracted to livestock facilities during winter (Johnson and Glahn, 1994; Linz et al., 2007); however, the temporal pattern of contamination with excrement and recovery of pathogens in relation to the mass of droppings are not well understood. Such information will allow livestock managers to identify the times of greatest risk of pathogen spread from starlings to cattle so that appropriate management activities can be implemented. 
The objectives of this study were to 1) understand the temporal pattern of contamination of cattle feed by European starling excrement on dairy farms and 2 ) evaluate the temporal pattern in recovering $E$. coli O157:H7 or Salmonella spp. from bird droppings and its relation to the absolute mass of excrement recovered from these dairy farms.

\section{MATERIALS AND METHODS}

\section{Study Design}

A longitudinal study was conducted on 15 dairy farms located in Wayne and Holmes counties, Ohio, from July 2007 to October 2008. In this pilot study, farms with greater than 125 milking cows were selected from a larger project involving 150 dairy farms. Herd size was limited to a common size for the industry in Ohio to adjust for possible management differences between small- and large-scale operations that may influence the extent of starling attraction to the farms. One open-topped bird feeder tray $\left(0.28 \mathrm{~m}^{2}\right)$ was filled with a commercially available bird feed and placed in an elevated area near a cattle-feeding site. The tray was emptied monthly and refilled with fresh feed. Total accumulation of excrement from the trays was weighed monthly for 12 consecutive months, except for one farm, for which sampling was missed in November 2007. The proportion of starling excrement that tested positive for E. coli O157:H7 or Salmonella spp. was determined.

Information regarding herd management from these 15 farms was collected from a questionnaire administered by our group for the larger project involving 150 farms (Cernicchiaro et al., 2012). Participating producers reported that their farms had a history of problems associated with the presence of starlings. All studied farms had free-stall barns. Cattle were fed indoors, with the exception of one farm, where cattle were fed both inside and outside the barn. Except for one farm that removed manure once daily and another that removed it less frequently, all farms removed cattle manure after every milking. The relative frequency of bird species visiting the farms was also documented (Cernicchiaro et al., 2012).

\section{Pathogen Detection}

Escherichia coli 0157:H7 Isolation from Starling Excrement. Total accumulation of excrement was thoroughly mixed, and $10 \mathrm{~g}$, if available, was subsampled from the total for enrichment. Buffered glycerol $(300 \mu \mathrm{L})$ was added to $1 \mathrm{~mL}$ of the homogenized slurry, then mixed and stored at $-80^{\circ} \mathrm{C}$. The remainder of the slurry was incubated for $24 \mathrm{~h}$ at $42^{\circ} \mathrm{C}$ for im- munomagnetic separation. The immunomagnetic-separation beads were then plated onto cefixime-tellurite sorbitol MacConkey plates and incubated for $24 \mathrm{~h}$ at $37^{\circ} \mathrm{C}$. Up to 5 suspect colonies (white) per sample from the cefixime-tellurite sorbitol MacConkey plates were transferred to EC MUG plates (EC media: NeogenAcumedia Manufacturers Inc., Lansing, MI; MUG: Biosynth AG, Staad, Switzerland) and incubated for $24 \mathrm{~h}$ at $37^{\circ} \mathrm{C}$. The MUG negative isolates (not glowing) were transferred to MacConkey plates and incubated for 24 $\mathrm{h}$ at $37^{\circ} \mathrm{C}$. Lactose positive isolates (purple colonies) were confirmed for $\mathrm{O} 157$ antigen using a latex agglutination assay (Oxoid Ltd., Nepean, ON, Canada).

Salmonella Isolation from Starling Excrement. One milliliter of buffered peptone water was added to the frozen slurry $(300 \mu \mathrm{L})$ and then incubated for $24 \mathrm{~h}$ at $37^{\circ} \mathrm{C}$. One milliliter of the buffered peptone water enrichment was added to $10 \mathrm{~mL}$ of tetrathionate broth and incubated for $48 \mathrm{~h}$ at $37^{\circ} \mathrm{C}$. Ten microliters of the enriched tetrathionate broth was added to $10 \mathrm{~mL}$ of RappaportVassiliadis R10 broth and incubated for $24 \mathrm{~h}$ at $37^{\circ} \mathrm{C}$. A loopful of the enriched Rappaport-Vassiliadis R10 broth was streaked onto XLT-4 agar plates and incubated for $24 \mathrm{~h}$ at $37^{\circ} \mathrm{C}$. The XLT- 4 plates were screened for suspect colonies (black) and then transferred to triple sugar iron agar slants, urea slants, and Simmons citrate slants; all slants were incubated for $24 \mathrm{~h}$ at $37^{\circ} \mathrm{C}$. Samples that had 1) a red slant, yellow butt, gas production, and H2S production on triple sugar iron slants; 2) no growth on urea slants; and 3) turned blue on the Simmons citrate slants were positive for Salmonella.

\section{Statistical Analysis}

Descriptive Statistics. Data were entered into an Excel 2007 (Microsoft Corporation, Redmond, WA) spreadsheet and transferred to STATA Intercooled 11.2 statistical software (StataCorp LP, College Station, TX) for analyses. The weights of the excrement recovered from each farm every month were converted to a standard score (Z-score). The standard score was calculated as the difference between the monthly weight of the excrement and the mean weight of excrement over 12 consecutive months for a specific farm, divided by the standard deviation of the weight of excrement recovered from the same farm (Gravetter and Wallnau, 2008). The number of birds visiting each farm can vary, and consequently the total mass of excrement can vary with temporal and farm-related effects. Standardizing weights removed these farm effects. Standard score values make visual assessment of the monthly trend of the amount of excrement per farm easier by comparing the deviation from the annual mean of each farm for each month. 
Multilevel Model. Linear regression models with a random intercept for farm were computed to examine the association between the absolute weight of excrement recovered each month or the farm-specific standard score for the weight of excrement, and month or season, after controlling for year. Season was categorized into winter (December 21 to March 21), spring (March 22 to June 21), summer (June 22 to September 21), and fall (September 22 to December 20).

A multilevel linear regression model with a first-order autoregressive correlation structure to account for time dependence was also constructed and compared with the simpler random intercept model in terms of model fit using Akaike's information criterion and Bayesian information criterion. Contrasts, using the lincom command in STATA, were computed to determine whether significant differences existed in mass of excrement accumulated between different months or seasons. Model fit was examined graphically by assessing the normality of the best linear unbiased predictors and the normality and homogeneity of variance of the standard residuals. The best linear unbiased predictors and standard residuals were plotted against predicted values to identify outliers (i.e., standard residuals $>3$ or $<-3$ ). Potential outliers were examined for recording errors. The model was also run without the identified outliers to assess their influence on the model.

Exact Logistic Regression. Exact logistic regression was used to determine whether an association between recovering E. coli O157:H7 or Salmonella spp. was present and the amount of excrement recovered and season (winter vs. the rest of the seasons). The odds ratio showing the association was reported. Exact logistic regression was chosen due to the small number of positive masses. All statistical tests were 2-tailed with $\alpha=0.05$ for statistical significance.

Space-Time Scan Statistic. The spatial scan statistic was performed using SaTScan version 8.0 (Martin Kulldorff and Information Management Services Inc., Boston, MA) to detect space-time clusters of contamination by excrement. A retrospective space-time scan using the normal model was applied to identify high excrement clusters based on the standard score for the weight of excrement. This statistic was applied to monthly data collected from July 2007 through October 2008. The maximum temporal and spatial scanning windows were $50 \%$ of the study period and samples, respectively. The null hypothesis was that contamination with excrement was randomly distributed within space and time. The space-time scan was set to detect higher scores within the space-time scanning window compared with scores outside the window at $\alpha=0.05$. Statistical significance was determined using Monte Carlo simulation with 999 replications. The results of the scan statistics were mapped using ArcGIS 9.2 (ESRI, Redlands, CA).

\section{RESULTS}

\section{Descriptive Findings}

A total of 179 pool of starling excrement were recovered during the study period. The total amount of starling excrement recovered monthly from each farm ranged from 0 to $279.3 \mathrm{~g}$, mean $=10.76 \mathrm{~g}(95 \% \mathrm{CI}$ : $6.19-15.33 \mathrm{~g}$ ), median $=1.8 \mathrm{~g}$ (interquartile range: $0.1-6.2 \mathrm{~g})$.

Five excrement samples $(2.79 \%, 5 / 179)$ were positive for E. coli O157:H7. Escherichia coli O157:H7 was recovered from bird-feed trays on 4 farms: once from farm 1 (August 2007), once from farm 7(August 2007), twice from farm 9 (December 2007, August 2008), and once from farm 14 (December 2007; Figure 1). Salmonella was isolated twice $(1.12 \%, 2 / 179)$ from the same birdexcreta collection tray on subsequent months (September and October 2007).

The highest mean amount of contamination by excrement was observed in January, followed by December and March (Table 1). For the standard score for the weight of excrement, higher contamination for most of the farms was in January and December (Figure 1).

\section{Multilevel Model}

For the models that examined the association between month and the absolute weight of excrement recovered each month or the standard score for the weight of excrement, the coefficients from the models with a first-order autoregressive correlation structure were appreciably different from the random intercept model. Moreover, the Akaike's information criterion and Bayesian information criterion values for the latter models were smaller (Table 2). Therefore, only the results for multilevel linear regression model with the simpler correlation structure are reported.

The amount of contamination, as measured by the absolute weight of excrement recovered each month, was significantly higher in January compared with all other months except March and December, for which no significant differences were observed (Table 3). The amount of contamination in March was significantly higher than the amount recovered in May, June, and July; the amount in December was also significantly higher than in October (Table 4). For the standard score for weight of excrement, the score was significantly higher in January compared with all other months except December (Table 3). March and December were significantly higher than most of the other months (Ta- 
Table 1. Summary of the amount of starling excreta recovered each month on 15 Ohio dairy farms

\begin{tabular}{lccc}
\hline Month & Mean $(\mathrm{g})$ & Median $(\mathrm{g})$ & $\mathrm{IQR}^{1}(\mathrm{~g})$ \\
\hline January & 30.26 & 11.00 & $4.10-21.05$ \\
February & 9.98 & 4.10 & $0.15-12.85$ \\
March & 21.57 & 4.10 & $1.20-16.15$ \\
April & 8.55 & 3.30 & $0.45-5.80$ \\
May & 1.79 & 1.20 & $0.10-2.75$ \\
June & 1.25 & 1.00 & $0.60-1.90$ \\
July & 3.47 & 0.95 & $0.10-2.40$ \\
August & 7.81 & 1.60 & $0.10-2.40$ \\
September & 8.33 & 1.40 & $0-5.08$ \\
October & 4.53 & 0.40 & $0.10-3.75$ \\
November & 10.07 & 1.00 & $0-4.40$ \\
December & 21.73 & 13.50 & $0.60-22.1$ \\
\hline
\end{tabular}

${ }^{1}$ Interquartile range.

ble 4). The remainder of the months were not significantly different with respect to the absolute excrement weight recovered each month or the standard score for weight of excrement.

When season was examined, the amount of contamination, as measured by the absolute weight of excrement recovered each month, was higher in the winter compared with all other seasons except the fall, for which the difference was not statistically significant. For the standard score for the weight of excrement, the amount of contamination in the winter was significantly higher than the rest of the seasons in a year (Table 5). Year was neither a confounder nor a significant predictor. The remainder of the seasons were not significantly different with respect to the absolute weight of excrement recovered each month or the standard score for fecal weight.

For the multilevel linear regression models that examined the association between the absolute weight of excrement recovered each month and month or season,

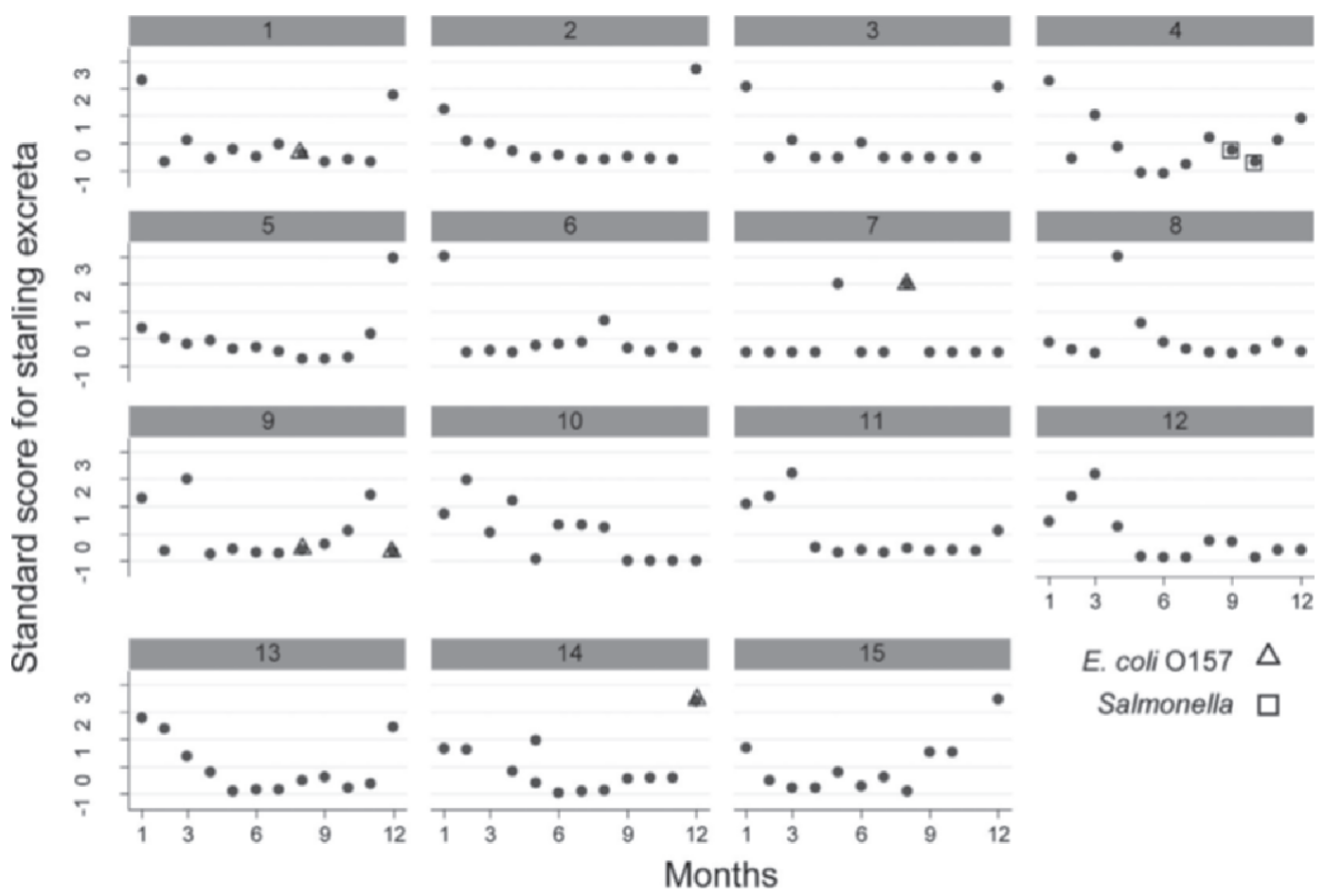

Graphs by Farm

Figure 1. Standard score for starling excrement weight recovered each month for 12 consecutive months from a bird-feeder tray located near a cattle-feeding site on 15 Ohio dairy farms. The standard score was calculated as the difference between the monthly excreta weight and the mean excreta weight over 12 consecutive months for a specific farm, divided by the standard deviation of excreta weights recovered from the same farm. E. coli= Escherichia coli. 
Table 2. The Akaike's information criterion (AIC) and Bayesian information criterion (BIC) for the association between the absolute weight of excrement recovered each month or the standard score for the weight of excrement, and month or season, using the simpler multilevel linear regression model and the model with a first-order autoregressive correlation structure

\begin{tabular}{lrr}
\hline Model (outcome variable) & AIC & \multicolumn{1}{c}{ BIC } \\
\hline Multilevel (absolute excrement weight) $^{1}$ & $1,588.33$ & $1,636.15$ \\
Autoregressive (absolute excrement weight) $^{1}$ & $1,588.32$ & $1,639.31$ \\
Multilevel (Z-score for excrement weight) $^{2}$ & 467.36 & 515.17 \\
Autoregressive (Z-score for excrement weight) $^{2}$ & 468.64 & 519.63 \\
Multilevel (absolute excrement weight) $^{3}$ & $1,639.10$ & $1,664.59$ \\
Autoregressive (absolute excrement weight) $^{3}$ & $1,663.44$ & $1,685.75$ \\
Multilevel (Z-score for excrement weight) $^{4}$ & 466.00 & 488.31 \\
Autoregressive (Z-score for excrement weight) $^{4}$ & 476.26 & 498.57 \\
\hline
\end{tabular}

${ }^{1}$ Association between month and the absolute weight of excrement recovered each month, after controlling for year.

${ }^{2}$ Association between month and the standard score (Z-score) for the weight of excrement recovered each month, after controlling for year.

${ }^{3}$ Association between season and the absolute weight of excrement recovered each month, after controlling for year.

${ }^{4}$ Association between season and the standard score (Z-score) for the weight of excrement recovered each month, after controlling for year.

one farm was identified as an outlier. The standard residual in May was -3.4 , June -3.5 , December 3.2, March 3.7, and January 8.1. The larger standard residual in winter was 8.3 , spring -3.6 and 4.2 , fall 3.5 . After running the multilevel model without this farm, the amount of contamination, as measured by the absolute weight of excrement recovered each month, was significantly higher in the winter than the rest of the seasons. This farm was only $3.8 \mathrm{~km}$ away from one of the night-roosting sites and it is the only farm for which manure was removed daily instead of after each milking. No outliers were identified for the models assessing the association between the standard score for the weight of excrement and month or season.

\section{Exact Logistic Regression and Space-Time Scan Statistic}

Using exact logistic regression, the odds of recovering a pathogen in a mass of excrement increased with the amount of excrement recovered (odds ratio $=1.02$; $95 \% \mathrm{CI}=1.01-1.04 ; P=0.004)$ and decreased if the excrement was recovered in the winter compared with the rest of the seasons [odds ratio (median unbiased estimate $)=0.10 ; 95 \% \mathrm{CI}=0-0.89 ; P=0.022]$.

Based on the standard score for the weight of excrement recovered each month, a statistically significant $(P=0.002)$ spatio-temporal cluster was present of high contamination with excrement that encompassed

Table 3. Linear regression model with a random intercept for farm of the association between the absolute weight of excrement recovered each month from a bird-feeder tray in grams or the standard score for the weight of excrement, and excrement collection month

\begin{tabular}{|c|c|c|c|c|c|c|}
\hline Variable & \multicolumn{3}{|c|}{ Absolute weight of feces (g) } & \multicolumn{3}{|c|}{ Standard score for fecal weight } \\
\hline January & Referent & & & Referent & & \\
\hline March & -8.69 & 0.26 & $-23.96,6.57$ & -0.71 & 0.016 & $-1.30,-0.13$ \\
\hline April & -21.71 & 0.005 & $-36.97,-6.44$ & -1.18 & $<0.001$ & $-1.77,-0.60$ \\
\hline May & -28.47 & $<0.001$ & $-43.74,-13.21$ & -1.50 & $<0.001$ & $-2.08,-0.92$ \\
\hline September & -24.78 & 0.009 & $-43.44,-6.12$ & -1.43 & $<0.001$ & $-2.12,-0.74$ \\
\hline October & -27.42 & 0.004 & $-46.21,-8.64$ & -1.46 & $<0.001$ & $-2.15,-0.77$ \\
\hline November & -22.59 & 0.030 & $-43.02,-2.14$ & -1.25 & 0.001 & $-1.99,-0.49$ \\
\hline December & -10.64 & 0.31 & $-31.13,9.85$ & -0.04 & 0.92 & $-0.79,0.71$ \\
\hline $2007^{1}$ & Referent & & & Referent & & \\
\hline $2008^{1}$ & -2.11 & 0.76 & $-15.95,11.52$ & 0.24 & 0.32 & $-0.23,0.71$ \\
\hline
\end{tabular}

${ }^{1}$ Year of excrement collection. 
Table 4. Contrasts of significantly different excrement accumulations between months from the linear regression model with a random intercept for farm, of the association between the absolute weight of excrement recovered each month from a bird-feeder tray in grams or the standard score for the weight of excrement, and excrement collection month

\begin{tabular}{lccc}
\hline Variable & Coefficient & $P$-value & $95 \%$ CI \\
\hline March vs. May $^{1}$ & 19.78 & 0.011 & $4.52-35.04$ \\
March vs. June $^{1}$ & 19.26 & 0.011 & $4.42-34.09$ \\
March vs. July $^{1}$ & 19.97 & 0.016 & $3.76-36.18$ \\
December vs. October $^{1}$ & 16.78 & 0.034 & $1.28-32.29$ \\
February vs. June $^{2}$ & 0.65 & 0.020 & $0.10-1.19$ \\
February vs. July $^{2}$ & 0.64 & 0.034 & $0.47-1.23$ \\
March vs. May $^{2}$ & 0.79 & 0.006 & $0.23-1.35$ \\
March vs. June $^{2}$ & 0.92 & 0.001 & $0.38-1.46$ \\
March vs. July $^{2}$ & 0.91 & 0.003 & $0.32-1.50$ \\
March vs. August $^{2}$ & 0.59 & 0.044 & $0.02-1.17$ \\
March vs. September $^{2}$ & 0.72 & 0.035 & $0.05-1.39$ \\
March vs. October $^{2}$ & 0.75 & 0.028 & $0.08-1.42$ \\
December vs. February $^{2}$ & 0.95 & 0.010 & $0.23-1.67$ \\
December vs. April $^{2}$ & 1.14 & 0.002 & $0.42-1.87$ \\
December vs. May $^{2}$ & 1.46 & $<0.001$ & $0.74-2.18$ \\
December vs. June $^{2}$ & 1.59 & $<0.001$ & $0.89-2.30$ \\
December vs. July $^{2}$ & 1.59 & $<0.001$ & $0.91-2.26$ \\
December vs. August $^{2}$ & 1.26 & $<0.001$ & $0.66-1.87$ \\
December vs. September $^{2}$ & 1.39 & $<0.001$ & $0.78-2.01$ \\
December vs. October $^{2}$ & 1.42 & $<0.001$ & $0.85-1.99$ \\
December vs. November $^{2}$ & 1.21 & $<0.001$ & $0.65-1.77$ \\
\hline
\end{tabular}

${ }^{1}$ Absolute weight of excrement recovered each month from a bird-feeder tray ( $\mathrm{g}$ ) versus the excrement collection month.

${ }^{2}$ Standard score for the weight of excrement versus the excrement collection month.

7 farms from Wayne county with a 12.96 -km radius around its center during the December 2007 to March 2008 period (Figure 2).

\section{DISCUSSION}

The European starling has been implicated in the contamination of cattle feed and the farm environment with excreta, resulting in the subsequent spread of zoonotic pathogens (Johnson and Glahn, 1994; Linz et al., 2007; LeJeune et al., 2008). In this study, we set out to determine the temporal pattern of contamination of cattle feed by starling excrement on Ohio dairy farms and to evaluate the temporal pattern of recovering $E$. coli O157:H7 or Salmonella spp. in relation to the absolute mass of starling excrement recovered.
We found that the amount of contamination with starling excrement was higher in the winter compared with the other seasons. The space-time cluster of high mass of excrement detected from December to March also supports this finding. Our study was only conducted for a total of 16 mo, and comparisons of seasons over multiple years are required to thoroughly support the inference of a seasonal effect. However, these results agree with a recent survey on dairy farms in Pennsylvania, New York, and Wisconsin, for which the greatest wild-bird fecal contamination on these farms occurred between January and March (Shwiff et al., 2012). The greatest number of starlings present at feedlots and dairies has been observed during cold winter days when the movement of these birds was limited because of snow or freezing temperatures (Linz et al., 2007; Carl-

Table 5. Linear regression model with a random intercept for farm of the association between the absolute weight of excrement recovered each month from a bird-feeder tray in grams or the standard score for weight of excrement, and excrement collection season

\begin{tabular}{|c|c|c|c|c|c|c|}
\hline \multirow[b]{2}{*}{ Variable } & \multicolumn{3}{|c|}{ Absolute weight of feces (g) } & \multicolumn{3}{|c|}{ Standard score for fecal weight } \\
\hline & Coefficient & $P$-value & $95 \% \mathrm{CI}$ & Coefficient & $P$-value & $95 \% \mathrm{CI}$ \\
\hline Spring & -11.45 & 0.015 & $-20.68,-2.22$ & -0.88 & $<0.001$ & $-1.24,-0.52$ \\
\hline Summer & -13.52 & 0.006 & $-23.18,-3.86$ & -1.14 & $<0.001$ & $-1.51,-0.76$ \\
\hline Fall & -11.09 & 0.10 & $-24.46,2.29$ & -1.06 & $<0.001$ & $-1.57,-0.56$ \\
\hline $2007^{1}$ & Referent & & & Referent & & \\
\hline
\end{tabular}

${ }^{1}$ Year of excrement collection. 

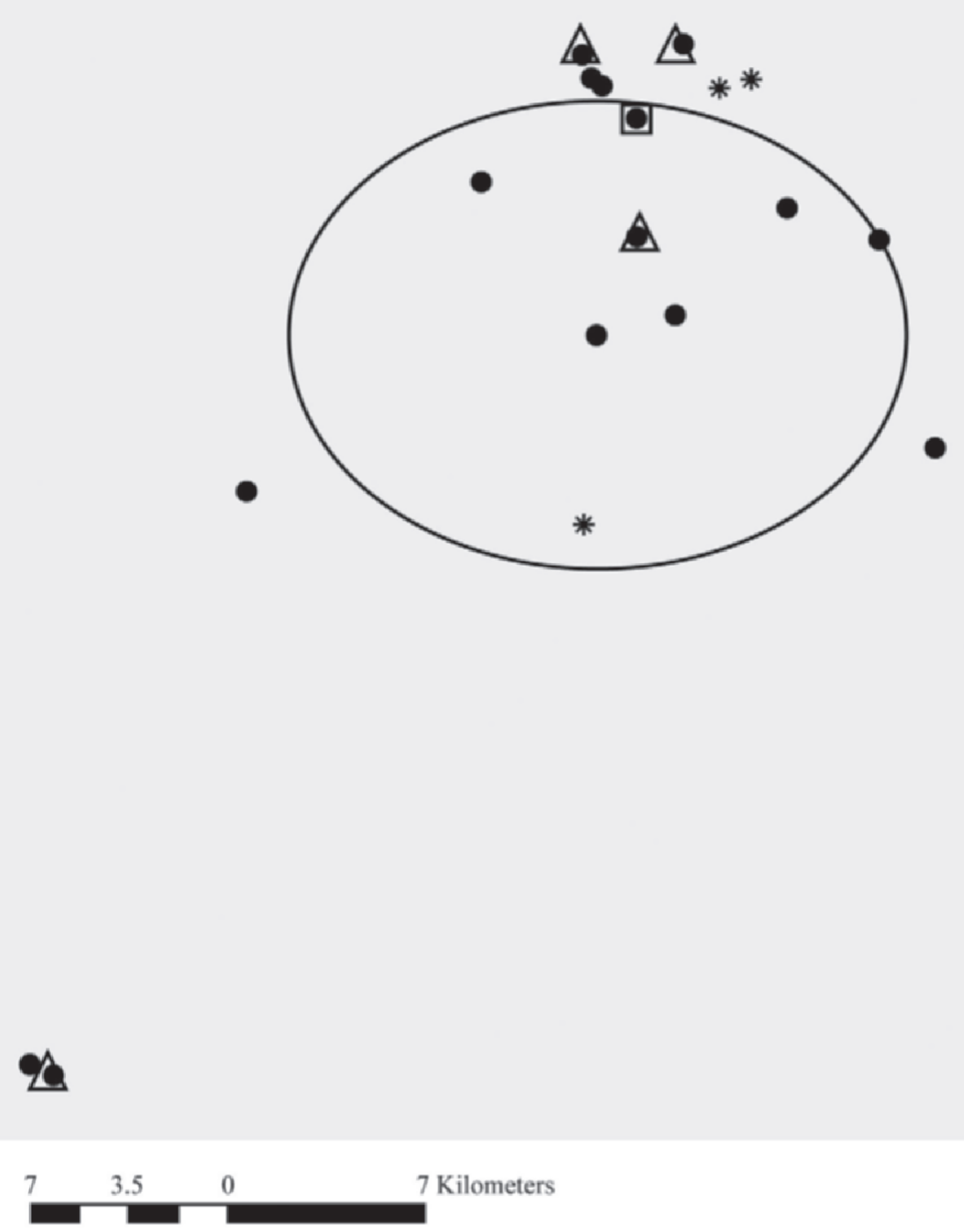

\section{* Roosting sites \\ $\square$ Salmonella positive farm \\ - Farms \\ $\Delta$ E. coli $\mathrm{O} 157$ positive farms}

Figure 2. Space-time cluster of high contamination with starling excreta that included 7 Ohio dairy farms from December 2007 to March 2008, based on the standard score for weight of starling excreta recovered each month for 12 consecutive months from a bird-feeder tray located near a cattle-feeding site. E. coli= Escherichia coli.

son et al., 2012); during winter, starlings roost in barns and bridges to shield themselves from harsh weather (Dolbeer et al., 1978).

The proportion of starling excreta that were positive for E. coli O157:H7 or Salmonella spp. was low and was similar to other studies that have documented the prevalence of these pathogens in starlings (Odermatt et al., 1998; Gaukler et al., 2008; LeJeune et al., 2008).
Escherichia coli O157 was isolated from $2.2 \%$ of starling intestinal contents in Ohio dairy farms (LeJeune et al., 2008) and $0.5 \%$ of cloacal swabs in central Kansas feedlots (Gaukler et al., 2008). No Salmonella spp. were recovered from the same swabs, whereas 1\% Salmonella spp. were recovered from fecal samples collected from Basel, Switzerland, starling night-roosting site (Odermatt et al., 1998). However, starlings travel in groups 
of hundreds to thousands of birds, thereby increasing the probability of fecal contamination and pathogen dissemination (Ballerini et al., 2008).

In our study, excrement masses from feed trays were collected monthly, and this might affect the survival of the bacteria. However, a prolonged survival period up to $1 \mathrm{yr}$ in ovine and bovine feces has been reported for E. coli O157:H7 in experimental and environmental settings (Kudva et al., 1998). Salmonella spp. have a longer survival time in the environment than $E$. coli (Winfield and Groisman, 2003). However, the survival period of E. coli O157:H7 in bird droppings is shorter than in bovine feces because of the higher level of ammonia in bird manure (Himathongkham et al., 2000). Nevertheless, cultures of excrement from starling birds that were experimentally inoculated with E. coli O157 were positive after 1 mo although the count of colony forming units decreased after $14 \mathrm{~d}$ (Kauffman and LeJeune, 2011).

Based on observational (Cernicchiaro et al., 2012; Shwiff et al., 2012) and experimental studies supported by molecular subtyping (Williams et al., 2011), researchers have found that various foodborne pathogens such as Salmonella and E. coli O157:H7 can be transmitted between cattle and starlings (Nielsen et al., 2004). In the current study, after controlling for season, the total amount of contamination by starling excrement from the masses in the feeder tray was related to the odds of recovering E. coli O157:H7 or Salmonella spp. This is consistent with the concept that the size of the starling population visiting the farm, and thus the amount of contamination, increases the odds of cattle being exposed to zoonotic pathogens. Our results appear to be consistent with other studies examining bird density (Carlson et al., 2012) and bacterial shedding of pathogens over time (Gaukler et al., 2009). Again, we acknowledge that our data do not cover multiple years, so our inferences concerning seasonality should be interpreted with caution.

Interestingly, the period when the feeder tray had the highest level of fecal contamination does not coincide with the period when cow fecal pats and bird excreta are most likely to be positive for several zoonotic pathogens, including E. coli O157:H7. Several studies indicated that the prevalence of E. coli and Salmonella in cattle was highest in the summer and early fall and lowest in the winter (Chapman et al., 1997; Hancock et al., 1997; Wells et al., 2001). The transmission to cattle is not expected to be influenced solely by amount of contamination with excrement. Transmission would be a factor of the amount of contamination in combination with the prevalence of the pathogen. Thus, if prevalence of a pathogen is high, the transmission can occur with minimal contamination. Similarly, if prevalence of a pathogen is low (e.g., in the winter), although the amount of contamination was high, risk for transmission would be negligible. Thus, a combination of sufficient prevalence and sufficient contamination could result in maximal transmission. However, the role the higher level of contamination of the farm environment with excrement in the winter has on the epidemiology of these pathogens in cattle still remains unclear.

The amount of excrement recovered from the feeder tray was an order of magnitude greater for 1 of the 15 farms. This outlier farm was only $3.8 \mathrm{~km}$ away from a major night-roosting site and was within less than 25 $\mathrm{km}$ from 3 other night-roosting sites. Winter roosting sites in Ohio can harbor up to 1,000,000 birds (LeJeune et al., 2008). Johnson and Glahn (1994) also indicated that starlings were mostly attracted to farms closest to their roosting sites and where feed was always accessible. However, additional factors could contribute to the accumulation of excrement. By generating a standard score for fecal weight, this farm was not an outlier in terms of the temporal pattern of contamination because the standard value was adjusted for the variability among farms in overall levels of fecal contamination.

We acknowledge that it is possible that some excreta could have been contributed by other bird species. However, on these farms, starlings were the most common species of birds (Cernicchiaro et al., 2012) and would have contributed most of the excrement. Starlings are reported to be the most frequent avian visitors to Ohio dairy farms (LeJeune et al., 2008). The prevalence and behavior of European starlings, and the typical feed management practices on dairy farms in the United States, strongly support our hypothesis of frequent feed contamination. It is possible, however, that feedborne dissemination of avian excreta is not the primary route of exposure to foodborne pathogens from birds to cattle. Birds also seek and use water sources on farms, and water troughs may be a common point source of exposure to E. coli O157 (Shere et al., 1998; LeJeune et al., 2001). However, because water troughs are placed in cattle-accessible areas, collection of excreta from water troughs that do not have direct contact with cattle was not possible. Furthermore, the dissolution of excrement in the water would preclude quantification of bird-specific contamination.

This study shows that the level of contamination of cattle feed by starling excrement was highest in the winter, whereas the odds of recovery of E. coli O157:H7 or Salmonella spp. from the excrement of these birds was lower in the winter compared with the rest of the seasons. Furthermore, the total amount of contamination with excrement was related to the odds of recovering a pathogen after controlling for season. The period 
when contamination was highest (i.e., winter) and the risk of feed exposure to a zoonotic pathogen was highest (i.e., spring, summer, and fall) do not appear to match. These results are important for the development of risk assessment and infectious-disease models used for planning farm biosecurity policies and procedures.

\section{ACKNOWLEDGMENTS}

This research was supported by the USDA through the National Research Initiative (USDA-NRI), Epidemiological Approaches to Food Safety Grant \# 200601227. The Canada Foundation for Innovation and the Ontario Research Fund supported the computational infrastructure. The authors thank Natalia Cernicchiaro for her valuable assistance.

\section{REFERENCES}

Ballerini, M., N. Cabibbo, R. Candelier, A. Cavagna, E. Cisbani, I. Giardina, A. Orlandi, G. Parisi, A. Procaccini, M. Viale, and V. Zdravkovic. 2008. Empirical investigation of starling flocks: A benchmark study in collective animal behaviour. Anim. Behav. $76: 201-215$.

Carlson, J. C., J. W. Ellis, S. K. Tupper, A. B. Franklin, and G. M. Linz. 2012. The effect of European starlings and ambient air temperature on Salmonella enterica contamination within cattle feed bunks. Human-Wildl. Interact. 6:64-71.

Carlson, J. C., A. B. Franklin, D. R. Hyatt, S. E. Petit, and G. M. Linz. 2011. The role of starlings in the spread of Salmonella within concentrated animal feeding operations. J. Appl. Ecol. 48:479486. http://dx.doi.org/10.1111/j.1365-2664.2010.01935.x.

Cernicchiaro, N., D. L. Pearl, S. A. McEwen, L. Harpster, H. J. Homan, G. M. Linz, and J. T. LeJeune. 2012. Association of wild bird density and farm management factors with the prevalence of $E$. coli O157 in dairy herds in Ohio (2007-2009). Zoonoses Public Health 59:320-329. http://dx.doi.org/10.1111/j.1863-2378.2012.01457.x.

Chapman, P. A., C. A. Siddons, A. T. C. Malo, and M. A. Harkin. 1997. A 1-year study of Escherichia coli O157 in cattle, sheep, pigs and poultry. Epidemiol. Infect. 119:245-250.

Daniels, M. J., M. R. Hutchings, and A. Greig. 2003. The risk of disease transmission to livestock posed by contamination of farm stored feed by wildlife excreta. Epidemiol. Infect. 130:561-568.

Dolbeer, R. A., P. P. Woronecki, A. R. Stickley, and S. B. White. 1978. Agricultural impact of a winter population of blackbirds and starlings. Wilson Bull. 90:31-44.

Feare, C. J., P. Douville de Franssu, and S. J. Peris. 1992. The starling in Europe: Multiple approaches to a problem species. Proc. Vert. Pest Conf. 15:83-88.

Gaukler, S. M., H. J. Homan, N. W. Dyer, G. M. Linz, and W. J. Bleier. 2008. Pathogenic diseases and movements of wintering European starlings using feedlots in central Kansas. Proc. Vert. Pest Conf. 23:280-282.

Gaukler, S. M., G. M. Linz, J. S. Sherwood, N. W. Dyer, W. J. Bleier, Y. M. Wannemuehler, L. K. Nolan, and C. M. Logue. 2009. Escherichia coli, Salmonella, and Mycobacterium avium ssp. paratuberculosis in wild European starlings at a Kansas cattle feedlot. Avian Dis. 53:544-551. http://dx.doi.org/10.1637/8920-050809-Reg.1.

Gravetter, F. J., and L. B. Wallnau. 2008. Essentials of Statistics for Behavioral Science. 6th ed. Thomson Learning Inc., Belmont, CA.

Hancock, D. D., T. E. Besser, D. H. Rice, D. E. Herriott, and P. I Tarr. 1997. A longitudinal study of Escherichia coli O157 in fourteen cattle herds. Epidemiol. Infect. 118:193-195.
Himathongkham, S., H. Riemann, S. Bahari, S. Nuanualsuwan, P. Kass, and D. O. Cliver. 2000. Survival of Salmonella typhimurium and Escherichia coli O157:H7 in poultry manure and manure slurry at sublethal temperatures. Avian Dis. 44:853-860.

Johnson, R. J., and J. F. Glahn 1994. European starlings. Page 72 in The Handbook: Prevention and Control of Wildlife Damage. S. E. Hygnstrom, R. M. Timm, and G. E. Larson, ed. University of Nebraska-Lincoln.

Kauffman, M. D., and J. LeJeune. 2011. European starlings (Sturnus vulgaris) challenged with Escherichia coli O157 can carry and transmit the human pathogen to cattle. Lett. Appl. Microbiol. 53:596-601.

Kudva, I. T., K. Blanch, and C. J. Hovde. 1998. Analysis of Escherichia coli O157: $\mathrm{H} 7$ survival in ovine or bovine manure and manure slurry. Appl. Environ. Microbiol. 64:3166-3174.

LeJeune, J., J. Homan, G. Linz, and D. L. Pearl. 2008. Role of the European starling in the transmission of E. coli $\mathrm{O} 157$ on dairy farms. Proc. Vert. Pest Con. 23:31-34.

LeJeune, J. T., T. E. Besser, D. H. Rice, and D. D. Hancock. 2001. Methods for the isolation of water-borne Escherichia coli O157. Lett. Appl. Microbiol. 32:316-320.

Linz, G. M., H. J. Homan, S. M. Gaukler, L. B. Penry, and W. J. Bleier. 2007. European starlings: A review of an invasive species with far-reaching impacts. Pages 378-386 in Managing Invasive Vertebrate Species: Proceedings of an International Symposium. G. W. Witmer, W. C. Pitt, and K. A. Fagerstone, ed. USDA/ APHIS/Natl. Wildl. Res. Center, Fort Collins, CO.

Nielsen, E. M., M. N. Skov, J. J. Madsen, J. Lodal, J. B. Jespersen, and D. L. Baggesen. 2004. Verocytotoxin-producing Escherichia coli in wild birds and rodents in close proximity to farms. Appl. Environ. Microbiol. 70:6944-6947.

Odermatt, P., S. Gautsch, D. Rechsteiner, R. Ewald, D. Haag-Wackernagel, R. Muhlemann, and M. Tanner. 1998. [Swarms of starlings in Basel: A natural phenomenon, a nuisance or a health risk?] Gesundheitswesen 60:749-754.

Pimentel, D., L. Lach, R. Zuniga, and D. Morrison. 2000. Environmental and economic costs of nonindigenous species in the United States. Bioscience 50:53-65.

Sanad, Y. M., G. J. Closs, A. Kumar, J. T. Lejeune, and G. Rajashekara. 2013. Molecular epidemiology and public health relevance of Campylobacter isolated from dairy cattle and European starlings in Ohio, USA. Foodborne Pathog. Dis. 10:229-236.

Shere, J. A., K. J. Bartlett, and C. W. Kaspar. 1998. Longitudinal study of Escherichia coli O157:H7 dissemination on four dairy farms in Wisconsin. Appl. Environ. Microbiol. 64:1390-1399.

Shwiff, S. A., J. C. Carlson, J. H. Glass, J. Suckow, M. S. Lowney, K. M. Moxcey, B. Larson, and G. M. Linz. 2012. Producer survey of bird-livestock interactions in commercial dairies. J. Dairy Sci. 95:6820-6829. http://dx.doi.org/10.3168/jds.2011-5216.

Van Donkersgoed, J., J. Berg, A. Potter, D. Hancock, T. Besser, D. Rice, J. LeJeune, and S. Klashinsky. 2001. Environmental sources and transmission of Escherichia coli O 157 in feedlot cattle. Can. Vet. J. $42: 714-720$.

Wells, S. J., P. J. Fedorka-Cray, D. A. Dargatz, K. Ferris, and A. Green. 2001. Fecal shedding of Salmonella spp. by dairy cows on farm and at cull cow markets. J. Food Prot. 64:3-11.

Wetzel, A. N., and J. T. LeJeune. 2006. Clonal dissemination of Escherichia coli $\mathrm{O} 157: \mathrm{H} 7$ subtypes among dairy farms in northeast Ohio. Appl. Environ. Microbiol. 72:2621-2626.

Williams, M. L., D. L. Pearl, and J. T. LeJeune. 2011. Multiple-locus variable-nucleotide tandem repeat subtype analysis implicates European starlings as biological vectors for Escherichia coli O157:H7 in Ohio, USA. J. Appl. Microbiol. 111:982-988.

Winfield, M. D., and E. A. Groisman. 2003. Role of non host environments in the lifestyles of Salmonella and Escherichia coli. Appl. Environ. Microbiol. 69:3687-3694. 